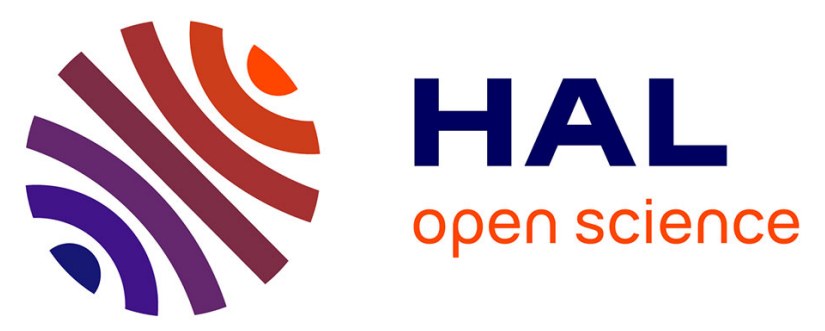

\title{
Social support from evaluative familiar persons - a buffer against stress? Preliminary evidence of neuroendocrine and psychological responses
}

Nicolas Mascret, Olivier Vors, Tanguy Marqueste, Remy Casanova, François Cury

\section{To cite this version:}

Nicolas Mascret, Olivier Vors, Tanguy Marqueste, Remy Casanova, François Cury. Social support from evaluative familiar persons - a buffer against stress? Preliminary evidence of neuroendocrine and psychological responses. Anxiety, Stress and Coping, 2019, 32 (5), pp.534-544. 10.1080/10615806.2019.1638680 . hal-02276587

\section{HAL Id: hal-02276587 \\ https: / hal-amu.archives-ouvertes.fr/hal-02276587}

Submitted on 2 Sep 2019

HAL is a multi-disciplinary open access archive for the deposit and dissemination of scientific research documents, whether they are published or not. The documents may come from teaching and research institutions in France or abroad, or from public or private research centers.
L'archive ouverte pluridisciplinaire HAL, est destinée au dépôt et à la diffusion de documents scientifiques de niveau recherche, publiés ou non, émanant des établissements d'enseignement et de recherche français ou étrangers, des laboratoires publics ou privés.

$$
\text { Copyright }
$$




\title{
Social support from evaluative familiar persons - a buffer against stress? Preliminary evidence of neuroendocrine and psychological responses
}

\author{
Nicolas Mascret, Olivier Vors, Tanguy Marqueste, Rémy Casanova \& François \\ Cury
}

To cite this article: Nicolas Mascret, Olivier Vors, Tanguy Marqueste, Rémy Casanova \& François Cury (2019) Social support from evaluative familiar persons - a buffer against stress? Preliminary evidence of neuroendocrine and psychological responses, Anxiety, Stress, \& Coping, 32:5, 534-544, DOI: $10.1080 / 10615806.2019 .1638680$

To link to this article: https://doi.org/10.1080/10615806.2019.1638680

里 Published online: 02 Jul 2019.

Submit your article to this journal $₫$

Џ Article views: 11

View Crossmark data ¿ 


\title{
Social support from evaluative familiar persons - a buffer against stress? Preliminary evidence of neuroendocrine and psychological responses
}

\author{
Nicolas Mascret ${ }^{\mathrm{a}, \mathrm{b}}$, Olivier Vors ${ }^{\mathrm{a}, \mathrm{b}}$, Tanguy Marqueste ${ }^{\mathrm{a}}$, Rémy Casanova ${ }^{\mathrm{a}}$ and François Cury ${ }^{\mathrm{a}}$ \\ ${ }^{a}$ Aix Marseille Univ, CNRS, ISM, Marseille, France; ${ }^{b}$ SFERE-Provence, FED 4238, Marseille, France
}

\begin{abstract}
Background and Objectives: Social support may have a stress-buffering effect when an individual is or could be negatively judged by others, but paradoxically may also exacerbate stress. The aim of our study was to examine these findings when social support was provided by a positive or negative evaluative audience composed of familiar and close others (teachers).

Design and Methods: 84 men were confronted with the Trier Social Stress Test for Groups through a 3 (negative, positive, no-audience) $\times 2$ (familiar, unfamiliar) experimental design with four measurement points of cortisol levels and state anxiety. We also tested whether closeness with the committee members predicted these variables for the participants in the familiar conditions.

Results: Using both a frequentist and a Bayesian approach, familiarity and social support did not have stress-buffering effects (or merely anecdotal effects) on cortisol levels but buffered self-reported anxiety only for the participants faced with a supportive audience composed of familiar persons. Closeness with the experimenters was not a significant predictor of the stress responses.

Conclusions: Because these results are preliminary evidence, further investigations into the relations between support provider and recipient during evaluative tasks would be worthwhile to better explain opposing findings found in this growing literature.
\end{abstract}

\section{ARTICLE HISTORY}

Received 31 May 2018

Revised 19 March 2019

Accepted 25 March 2019

\section{KEYWORDS}

Cortisol; trier social stress test; familiarity; anxiety; closeness; social-evaluative threat

Every day we are constantly observed and evaluated by the person(s) with whom we interact, and this evaluation may be a potential source of stress through social-evaluative threat (Frisch, Häusser, \& Mojzisch, 2015). Social support, namely the "provision of psychological and material resources intended to benefit an individual's ability to cope with stress" (Cohen, 2004, p. 676), may have strong stress-buffering effects reducing anxiety, neuroendocrine, and autonomic responses (for a review, see Taylor, 2007). Social support has beneficial effects which affect both the prevention of stress and the consequences of the stress response (Haslam, Reicher, \& Levine, 2012). Paradoxically, social support may also be ineffective and even detrimental, exacerbating stressful circumstances as a result of self-esteem threat. Indeed, social support may indicate that one is incapable of handling stressful events on one's own (Bolger \& Amarel, 2007). These mixed results may be partially explained by studying the relationship between the provider and recipient of social support (Frisch, Häusser, van Dick, \& Mojzisch, 2014), such as familiarity (i.e., the degree of exposure that one person has to another person; Reis, Maniaci, Caprariello, Eastwick, \& Finkel, 2011) and closeness (i.e., the feeling 
of intimacy and connection to the other person; Aron, Melinat, Aron, Vallone, \& Bator, 1997). Familiarity is also defined in the literature by trust, past history, mutual knowledge, belonging, or confidence between the parties (e.g., Jehn \& Shah, 1997). But we have retained the definition of Reis et al. (2011) because on the one hand the meta-analysis of Fuchs and Fuchs (1986) showed that familiarity in the educational context was mainly defined broadly (i.e., acquaintance with the teacher), and on the other hand the definitions of closeness - which implies a strong bond - and familiarity were effectively distinct in the present study. In general, a familiar stimulus (via unreinforced repetition) is mainly associated with an absence of negative consequences, a reduction of uncertainty, and a variety of preference judgments (Carr, Brady, \& Winkielman, 2017). But again, findings continue to be discussed in the social support domain. For example, social support provided by a close other induced higher cortisol levels for men - but not for women - comparatively to a stranger (Smith, Loving, Crockett, \& Campbell, 2009), whereas it induced reduced systolic blood pressure reactivity only when the close other did not simultaneously play an evaluative role (Kors, Linden, \& Gerin, 1997). In the previous studies, several paradigms were used to experimentally induce stress, such as the Trier Social Stress Test (TSST, Kirschbaum, Pirke, \& Hellhammer, 1993).

The TSST is the most often used paradigm to induce acute psychosocial stress in experimental settings (Allen, Kennedy, Cryan, Dinan, \& Clarke, 2014). A number of studies using the TSST (for a recent review, see Frisch et al., 2015) highlighted that (1) social support itself was often ineffective in buffering the neuroendocrine stress response following the TSST, (2) some moderators (e.g., verbal or nonverbal social support, emotional or instrumental social support) may positively influence this stress-buffering effect, and (3) social support did not buffer self-reported stress responses such as anxiety, which always remained high. In these studies, social support was provided by individuals who were not directly involved in the stressful tasks. But in some circumstances, the only source of social support is the "stressor" him- or herself. For example, stress responses may decrease or, on the contrary, increase when a teacher emotionally supports a student during an oral examination in school or at university (e.g., giving nonverbal positive feedback). Indeed, teachers may be considered familiar and close others by their students and they are also potential social support providers (Malecki \& Demaray, 2003). But to date no studies have experimentally investigated the effects of social support provided by a teacher to his/her students during a stressful evaluative task such as the TSST. Moreover, the studies examining the effects of social support provided by the stressor him/herself during the TSST are limited in number. A first study manipulated the social support provided by the evaluative TSST committee itself (Taylor et al., 2010). The authors demonstrated that an evaluative but supportive audience during the TSST - providing nonverbal social support - produced the same biological and psychological responses as an unsupportive audience, and stronger responses than a no-audience control. They also questioned the composition of the evaluative audience during the TSST: would the effects be the same with a supportive committee composed of familiar persons, rather than strangers? The aim of our study was to supply an answer to this question. Furthermore, Frisch et al. (2014) showed that social identity (i.e., perceived membership in a relevant social group) may explain the results of Taylor et al. (2010). They found that a shared social identity (i.e., a common interpretive framework and feelings of trust among members of a group) between participants and the supportive TSST committee buffered the neuroendocrine stress response, but not for the unsupportive TSST committee and self-reported strain, regardless of the attitude of the committee members. In this study, the confederates were students who played the role of the committee members, and shared social identity was experimentally induced. Questions about the neuroendocrine and psychological responses then arise regarding hierarchical differences between participants and the committee members and regarding pre-existing relationships between them, such as hierarchy and relationships between students and teachers.

Based on this literature, we may envisage the following hypotheses. First, following both Taylor et al.'s (2010) and Frisch et al.'s (2014) assumptions, we may hypothesize that only a supportive committee composed of familiar experimenters buffered the neuroendocrine stress response induced by the TSST, but not the psychological response. Secondly, the results of Frisch et al. (2014) suggest that 
the level of pre-existing familiarity between students and teacher may buffer the neuroendocrine stress response - but not the psychological response - only when the TSST committee is familiar and supportive. In this sense, the level of closeness (closeness implies more intimacy than a shared social identity) between participants and teachers may also buffer the neuroendocrine stress response for the participants who feel closest to their familiar and supportive teachers.

\section{Method}

\section{Participants}

First, half of the participants had to be with the two teachers/experimenters to test our hypotheses. Secondly, the participants had to participate voluntarily in the study. Thirdly, they had to meet the eligibility criteria of the present study. Based on Mascret et al.'s (2016) research, nine exclusion criteria were used: history of endocrine disorder, drugs abuse, drinking more than two glasses of alcohol a day, smoking more than five cigarettes a day, cardiovascular diseases, increased levels of chronic stress, medication intake, psychological distress, and reported medical illness. Consequently, sample sizes were determined on the basis of the maximum number of participants that could be recruited during the period of data collection. 104 participants originally volunteered to participate in the study. They had also to follow two kinds of instructions. During the twelve hours preceding the experiment, they must not use alcohol, not practice sport, and not take medication. One hour before the beginning of the experiment, they should not to brush their teeth, not eat, not drink (except water), and not smoke. 20 participants were excluded for nonobservance of these instructions (e.g., eating or smoking one hour before the experiment, $N=10$ ) and for a non-sufficient quantity of saliva provided during saliva collection $(N=10)$. The reasons for exclusion relate to the validity of the cortisol measure. Following the procedure used in some studies (e.g., Frisch et al., 2014; Lam, Dickerson, Zoccola, \& Zaldivar, 2009; Sollberger, Bernauer, \& Ehlert, 2016; von Dawans, Kirschbaum, \& Heinrichs, 2011), all data (including state anxiety scores) of excluded participants were deleted without running any analyses with them. Thus, the final sample consisted of 84 French men $\left(20.93 \pm 2.71\right.$ years; Body Mass Index $\left.23.19 \pm 3.88 \mathrm{~kg} / \mathrm{m}^{2}\right)$. All the participants were blind to the true nature of the study. The study was conducted in accordance with the Declaration of Helsinki and informed consent was obtained from the participants.

\section{Procedure}

All experimental sessions started in the afternoon between 14:00 and 17:00 to control the cortisol awakening response (Stalder et al., 2016) and lasted $90 \mathrm{~min}$. Participants were initially selected one month before the experiment and assigned to one of two conditions. In the first condition, called Familiar, participants $(N=44)$ were the two experimenters' own students, to whom they had taught a 120-hour course from the beginning of the academic year. No more participants were available according to this criterion. In the second condition, called Unfamiliar, the two experimenters were totally unknown to the participants $(N=40)$.

Then, participants were randomly assigned to one of three sub-conditions during the Trier Social Stress Test for Groups (TSST-G, von Dawans et al., 2011), either a TSST-G (1) with two unsupportive committee members (negative condition), (2) with two supportive committee members (positive condition), or (3) with no committee members (no-audience condition). The TSST-G is a group format of the TSST and induces acute psychosocial stress by requiring participants to perform a mock job interview and a surprise mental arithmetic test in front of a video camera, a microphone, and two experimenters wearing white lab coats (Allen et al., 2014). Following Taylor et al.'s (2010) procedure, the two experimenters in the negative condition provided nonverbal signs of boredom, nonverbal indications of frustration, and exchanged glances with each other implying negative assessments, whereas in the positive condition they leaned 
forward, smiled, expressed an interest in the presentation, and gave nonverbal indications of support and positive assessments. In the no-audience condition, participants faced the Placebo TSST-G (von Dawans et al., 2011), a control protocol from which social-evaluative threat and uncontrollability, the two most stressful components of the TSST (Dickerson \& Kemeny, 2004), were excluded. Regardless of condition, participants did not have any social interaction with one another throughout the experiment and were separated by mobile dividing walls. The TSST-G and the Placebo TSST-G were followed by a 25 -min recovery period. A $3 \times 2$ experimental design [(negative, positive, no-audience $) \times($ familiar, unfamiliar)] was used in this study, leading to six experimental conditions: unfamiliar/negative $(N=16)$, familiar/negative $(N=16)$, unfamiliar/ positive $(N=16)$, familiar/positive $(N=16)$, unfamiliar/no-audience $(N=8)$, and familiar/no-audience $(N=12)$. The last two conditions were control conditions and the same experimenters as in the TSST-G conditions provided the explanation of the two non-stressful tasks before leaving the room dedicated to the TSST-G. The experimenters who provided initial instructions were familiar for the participants in the familiar/no-audience condition and unfamiliar for the participants in the unfamiliar/no-audience condition.

The final sample was rather small. As seen previously, only two studies focused on the effect of the social support provided by the experimenters themselves, who had a positive or a negative attitude during the TSST. When the experimenters were unknown (Taylor et al., 2010) and when there was no shared social identity between the experimenters and the participants (Frisch et al., 2014), social support during the TSST did not have stress-buffering effects on cortisol levels. No differences were also expected in the present study irrespective of the sample size. Frisch et al. (2014) have conducted the only study with the TSST in which the experimenters had an induced shared social identity with the participants. Based on the effect size $(d=0.695)$ that they highlighted for cortisol levels in their study, we conducted a power calculation using $\mathrm{G}^{*}$ power version 3.1.9.3 (Faul, Erdfelder, Buchner, \& Lang, 2009). The results showed that a sample size of 24 participants per group would achieve an $80 \%$ power to detect an effect with an alpha of 0.05 . This was not the case in the present study, which may be considered underpowered. However, several reasons led us to overcome this result. First, because half of the participants must be familiar with the two teachers/experimenters according to the procedure (120-hour course from the beginning of the academic year), sample sizes were based on the maximum number of participants that could be recruited during the predetermined period of data collection, respecting all the exclusion criteria as explained above. The pool of potential familiar participants was exhausted. Secondly, some studies using the TSST have previously been conducted with experimental groups of ten participants and three or four measurement points (e.g., Pabst, Brand, \& Wolf, 2013; van den Bos, Harteveld, \& Stoop, 2009). Thirdly, the two groups with the lowest number of participants were control groups and many studies have confirmed that the Placebo TSST-G did not lead to a stress response (e.g., Frisch et al., 2015; von Dawans et al., 2011), irrespective of the sample size. Fourthly, a Bayesian approach was conducted complementary to the commonly applied frequentist approach (see Data Analysis section) because these statistics can be used specifically with reduced sample size (Depaoli, Rus, Clifton, van de Schoot, \& Tiemensma, 2017).

\section{Measures}

\section{Manipulation checks}

First, familiarity was verified one month before the experiment by a specific exclusion criterion using pictures of the two experimenters and a corresponding question ("Do you know these two men?"). Secondly, Taylor et al.'s (2010) manipulation check was used after the TSST-G to examine participants' perception of the experimenters' attitude during the positive and negative conditions. Participants rated the intensity of the three items on 7-point scales (e.g., "By the time your presentation was over, how supportive (7) or hostile (1) did the panel seem?"). Internal consistency was satisfactory (Cronbach's $a=.84$ ). 


\section{Cortisol sampling and assay}

Salivary free cortisol was assessed four times for each of the eighty-four participants: one minute before the TSST-G, following a 30-min rest period (T1), one minute after the end of the TSST-G or the Placebo-TSST-G (T2), ten minutes after (T3), and $20 \mathrm{~min}$ after (T4). The saliva was collected in plastic saliva collection tubes. Following exactly the procedure described in Mascret et al.'s (2016) study, intra-assay variation was $5.7 \pm 3.7 \%$ and inter-assay variation was $5.2 \pm 3.5 \%$.

\section{State anxiety}

The French version of the State-Trait Anxiety Inventory (STAI, Spielberger et al., 1993) was used to assess state anxiety, with twenty items (e.g., "I am tense") scored on a 4-point Likert scale (from Not at all to Very much so). This self-reported measure was assessed four times immediately after saliva collection. Internal consistency was satisfactory for each measurement point with Cronbach's alphas ranging from .81 to .94 .

\section{Closeness}

One month before the beginning of the experiment, the participants in the familiar conditions indicated on a specific 10-cm visual analog scale (Smith et al., 2009) how close they felt to their two teachers, from Not at all close to Very close.

\section{Data analyses}

Three kind of data analyses were conducted. First, the results of cortisol levels and self-reported anxiety were analyzed with 2 (familiar, unfamiliar) $\times 3$ (positive, negative, no-audience) $\times 4$ (measurement points) repeated-measures ANOVAs to reveal possible effects of familiarity, attitude of the committee members, and time of assessment, with $p<.05$ as a level of significance. The critical test of the first hypothesis is the test of a three-way interaction between audience $\mathrm{x}$ familiarity $\mathrm{x}$ time of measurement. Using Statistica 12 for PC, effect sizes were calculated with partial eta-squared $\left(\eta_{p}^{2}\right)$ and differences post-hoc with Newman-Keuls tests.

Secondly, and due to the rather small sample size in the present study, this commonly applied frequentist approach was complemented by Bayesian analyses, usable with reduced sample size (Depaoli et al., 2017). Moreover, this kind of analyses may corroborate significant effects, as well as providing evidence for null effects, and several models of the data are compared with the null model throughout different combinations of main effects and/or interactions of interest (Charpentier, Hindocha, Roiser, \& Robinson, 2016). The evidence for a model of interest relative to a null model ( 1 vs 0$)$ is represented by Bayes factors $\left(\mathrm{BF}_{10}\right)$ and the strength of evidence is interpreted with the magnitude of the $\mathrm{BF}_{10}$ (Charpentier et al., 2016; Jarosz \& Wiley, 2014): anecdotal $\left(1<\mathrm{BF}_{10}\right.$ $<3)$, substantial $\left(3<\mathrm{BF}_{10}<10\right)$, strong $\left(10<\mathrm{BF}_{10}<30\right)$, very strong $\left(30<\mathrm{BF}_{10}<100\right)$, or decisive $\left(B F_{10}>100\right)$. Natural logarithm $\left(\ln \left(B_{10}\right)\right)$ is used when $B_{10}$ is higher than 100 . To compare two models using the values above, the $\mathrm{BF}_{10}$ of the first model was divided by the $\mathrm{BF}_{10}$ of the second. This allows us to make a statement about an alternative hypothesis, rather than just the null hypothesis (Jarosz \& Wiley, 2014). To test the first hypothesis of the present study, we compared the basic model (with the variables audience (no-audience, positive, negative) and time, and their interaction) with the model including these variables complemented by familiarity and all the interactions between variables. In line with the main purpose of the present study, no sufficient informative priors were available in the literature for cortisol levels and self-reported anxiety induced by the TSST-G. Consequently, we based the Bayesian analyses on the default Bayes factors for ANOVA designs (Rouder, Morey, Speckman, \& Province, 2012). In program R (64 bit) version 3.4.2 (www.r-project.org) integrated in Rstudio version 1.1.414 (www.rstudio. com), we used the function anovaBF from the package "BayesFactor" version 0.9.12-4.2 (https:// richarddmorey.github.io/BayesFactor/). 
Thirdly and finally, we ran several hierarchical regression analyses using Statistica 12 for PC to test whether closeness with the two teachers predicts cortisol levels and anxiety scores for the participants in the familiar/positive and familiar/negative conditions.

\section{Results}

\section{Manipulation checks}

First, the forty participants in the unfamiliar condition answered that the two experimenters were totally unknown and all the participants in the familiar condition indicated that they knew the experimenters. Secondly, a one-way ANOVA $\left(F(3,60)=31.95, p<.001, \eta_{p}^{2}=.62\right)$ and NewmanKeuls tests revealed that the positive audience was indeed perceived to be more supportive by participants in the familiar and the unfamiliar conditions $(M=4.90, S D=1.09$, and $M=4.56, S D$ $=0.95$ respectively) than in the negative audience condition $(M=2.25, S D=1.00, p<.001$, and $M=2.60, S D=0.72, p<.001$ respectively), evidencing that the experimental manipulation was successful.

\section{Salivary cortisol levels}

A repeated-measures ANOVA conducted on the cortisol levels with the factors familiarity, audience (positive, negative, no-audience), and time of assessment revealed significant main effects of audience $\left(F(2,78)=10.35, p<.001, \eta_{p}^{2}=.21\right)$ and time $\left(F(3,234)=62.06, p<.001, \eta_{p}^{2}=.44\right)$. We also found significant two-way interactions between familiarity and audience $(F(2,78)=3.75, p=.028$, $\left.\eta_{p}^{2}=.09\right)$ and time and audience $\left(F(6,234)=7.37, p<.001, \eta_{p}^{2}=.16\right)$. For the critical test of the hypothesis, no significant three-way interaction was found between familiarity, audience, and time ( $p$ $=.799$ ). Newman-Keuls tests showed that (a) cortisol increases were not significant for the two control conditions ( $p=.415$ for the familiar condition and $p=.906$ for the unfamiliar condition), (b) cortisol levels significantly increased $(p<.001)$ between the beginning and the end of the TSST-G for the familiar/positive, familiar/negative, unfamiliar/positive, and unfamiliar/negative conditions, indicating that the TSST-G was indeed stressful for the participants regardless of condition, (c) cortisol levels were significantly higher in T2, T3, and T4 for the familiar/positive, familiar/negative, unfamiliar/ positive, and unfamiliar/negative conditions than for the two control conditions (with $p$-values ranging from <.001 to .033), except for one of the twelve measurement points which approached significance ( $p=.057$ ), (d) cortisol levels were not significantly higher in T2, T3, and T4 for the two familiar conditions than for the two unfamiliar conditions (with $p$-values ranging from .232 to .950), (e) cortisol levels were not significantly higher for the familiar/negative condition than for the familiar/positive condition (with $p$-values ranging from .481 to .836), and (f) cortisol levels were not significantly higher for the unfamiliar/negative condition than for the unfamiliar/positive condition (with $p$-values ranging from .778 to .970).

Bayesian analyses confirmed the main effects of audience (decisive effect, $\ln \left(\mathrm{BF}_{10}\right)=5.37$ ) and time (decisive effect, $\left.\ln \left(B_{10}\right)=67.77\right)$. They also confirmed the interaction effects between familiarity and audience (decisive effect, $\ln \left(B F_{10}\right)=5.62$ ) and between time and audience (decisive effect, $\ln \left(B F_{10}\right)=$ 84.70).

Additional Bayes factor analysis confirmed the non-significant results of the three-way interaction found with the ANOVA. Adding familiarity, the interaction between familiarity and audience, and the interaction between familiarity and time to the initial model (i.e., audience, time, and audience $x$ time) did not improve the model $\left(\mathrm{BF}_{10}\right.$ ratio between the two models $\left.=0.016\right)$. This result clearly indicated very strong evidence in favor of the null model $\left(0.01<\mathrm{BF}_{10}<0.033\right.$; Charpentier et al., 2016). Consequently, our hypothesis is rejected for the neuroendocrine response: a supportive committee composed of familiar experimenters did not buffer the neuroendocrine stress response induced by the TSST. 


\section{State anxiety}

A repeated-measures ANOVA conducted on the self-reported anxiety scores with the factors familiarity, audience, and time of assessment revealed significant main effects of audience $(F(2,78)=7.30$, $\left.p=.001, \eta_{p}^{2}=.16\right)$ and time $\left(F(3,234)=50.86, p<.001, \eta_{p}^{2}=.39\right)$. We also found significant two-way interactions between familiarity and time $\left(F(3,234)=3.31, p=.021, \eta_{p}^{2}=.04\right)$ and time and audience $\left(F(6,234)=6.65, p<.001, \eta_{p}^{2}=.15\right)$. Finally, for the critical test of the hypothesis, a three-way interaction between familiarity, audience, and time was found $\left(F(6,234)=2.48, p=.024, \eta_{p}^{2}=.06\right)$. Newman-Keuls tests mainly showed that (a) state anxiety remained stable in the two control conditions ( $p=.953$ for the familiar condition and $p=.996$ for the unfamiliar condition), (b) self-reported anxiety increased between the beginning and the end of the TSST-G in the familiar/negative, unfamiliar/negative, and unfamiliar/positive conditions ( $p<.001$ for each), but not significantly for the familiar/positive condition ( $p=.250$ ), (c) anxiety was significantly higher after the TSST-G for the familiar/negative, unfamiliar/positive, and unfamiliar/negative conditions than for the two control conditions (with $p$-values ranging from <.001 to .007), whereas no significant differences were found between the familiar/positive and control conditions $(p=.720)$, (d) anxiety in the unfamiliar/positive condition was significantly higher after the TSST-G than in the familiar/positive condition $(p=.049)$, (e) anxiety was significantly higher after the TSST-G for the familiar/negative condition than for the familiar/positive condition $(p=.021)$, whereas no significant differences were found between the unfamiliar/negative and unfamiliar/positive conditions $(p=.724)$.

Bayesian analyses confirmed the main effects of audience (very strong effect, $\mathrm{BF}_{10}=31.97$ ) and time (decisive effect, $\ln \left(\mathrm{BF}_{10}\right)=52.00$ ). They also confirmed the interaction effects between familiarity and time (very strong, $\mathrm{BF}_{10}=53.34$ ) and between time and audience (very strong, $\mathrm{BF}_{10}=64.95$ ). Finally, they confirmed the interaction between familiarity, audience, and time (decisive effect, In $\left.\left(B F_{10}\right)=66.46\right)$.

Confirming the significant three-way interaction previously found with the ANOVA, additional Bayes factor analyses showed that adding familiarity, the interaction between familiarity and audience, and the interaction between familiarity and time significantly (4.52 times) improved the initial model (i.e., audience, time, and audience $x$ time). The strength of this result was considered substantial $\left(3<\mathrm{BF}_{10}<10\right.$; Charpentier et al., 2016). Consequently, our hypothesis is rejected for the psychological response: a supportive committee composed of familiar experimenters buffered the psychological stress response induced by the TSST. Descriptive statistics are presented in Table 1 and results of the ANOVAs for state anxiety and salivary cortisol are presented in Figure 1.

\section{Closeness}

Baselines of cortisol levels were entered in Step 1 of the hierarchical regression analyses conducted for the participants in the familiar/positive and familiar/negative conditions. Condition (negative $=0$,

Table 1. Descriptive statistics

\begin{tabular}{|c|c|c|c|c|c|c|c|c|}
\hline \multirow[b]{2}{*}{ Conditions } & \multicolumn{4}{|c|}{ STAI scores } & \multicolumn{4}{|c|}{ Cortisol levels } \\
\hline & $\begin{array}{l}\text { STAI T1 } \\
\text { M SD }\end{array}$ & $\begin{array}{c}\text { STAI T2 } \\
\text { M SD }\end{array}$ & $\begin{array}{l}\text { STAI T3 } \\
\text { M SD }\end{array}$ & $\begin{array}{l}\text { STAI T4 } \\
\text { M SD }\end{array}$ & $\begin{array}{c}\text { Cortisol } \\
\text { T1 } \\
\text { M SD }\end{array}$ & $\begin{array}{c}\text { Cortisol } \\
\text { T2 } \\
\text { M SD }\end{array}$ & $\begin{array}{c}\text { Cortisol T3 } \\
\text { M SD }\end{array}$ & $\begin{array}{c}\text { Cortisol T4 } \\
\text { M SD }\end{array}$ \\
\hline Familiar / Negative & 30.505 .73 & 44.2510 .94 & 39.0612 .55 & 33.818 .44 & 6.291 .41 & 9.641 .19 & 10.663 .01 & 10.942 .83 \\
\hline Familiar / Positive & 30.255 .09 & 35.126 .92 & 30.817 .49 & 29.507 .57 & 6.561 .88 & 9.822 .76 & 11.103 .91 & 10.042 .82 \\
\hline $\begin{array}{l}\text { Familiar / No- } \\
\text { audience }\end{array}$ & 28.007 .60 & 29.428 .41 & 23.924 .76 & 25.676 .21 & 5.901 .04 & 7.220 .76 & 6.860 .97 & 6.381 .27 \\
\hline $\begin{array}{l}\text { Unfamiliar / } \\
\text { Negative }\end{array}$ & 29.065 .32 & 41.819 .92 & 30.448 .72 & 27.625 .60 & 5.751 .32 & 8.952 .10 & 9.391 .66 & 9.251 .26 \\
\hline Unfamiliar / Positive & 28.444 .93 & 42.8712 .26 & 32.127 .52 & 29.006 .16 & $5.910,98$ & 8.741 .35 & 9.162 .20 & 9.071 .78 \\
\hline $\begin{array}{l}\text { Unfamiliar / No- } \\
\text { audience }\end{array}$ & 30.444 .03 & 31.223 .35 & 26.443 .24 & 25.782 .68 & 6.881 .25 & 8.331 .01 & 8.071 .20 & 7.041 .22 \\
\hline
\end{tabular}



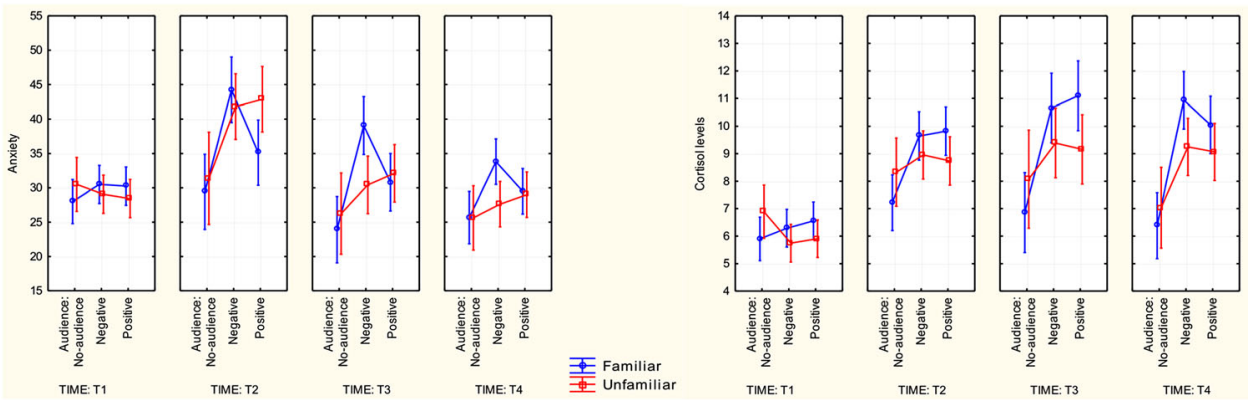

Figure 1. State anxiety scores and cortisol levels of participants depending on time of assessment and condition.

Notes. Cortisol levels are expressed in $\mathrm{nmol} / \mathrm{L}, \mathrm{T} 1=$ one minute before the TSST-G, following a 30-min rest period, $\mathrm{T} 2=$ one minute after the end of the TSST-G or the Placebo-TSST-G, T3 = ten minutes after, $\mathrm{T} 4=20 \mathrm{~min}$ after.

positive $=1$ ) was entered in Step 2. Closeness with the two experimenters was entered in Step 3. Finally, the interaction between condition and closeness was entered in Step 4. The results demonstrated that these variables did not significantly predict cortisol levels at T2, T3, and T4. The same procedure was conducted with the state anxiety scores and the results were similar. In sum, closeness was not a significant predictor of the stress response for the participants familiar with the two experimenters regardless of their positive or negative attitude.

\section{Discussion}

Social support provided by an unknown evaluative audience during the TSST did not show stressbuffering effects on cortisol levels, evidencing that the evaluative dimensions of the stressful tasks override the potential benefits of social support, replicating Taylor et al.'s (2010) surprising findings. But our study also demonstrated that the pattern was similar when social support was provided by familiar persons, rejecting our first hypothesis. Social support offered by the students' teachers who are simultaneously a source of threat was not effective at the neuroendocrine level. Receiving support from an evaluative familiar person or a stranger can exacerbate cortisol levels due to an acute threat to self-esteem when important and valued aspects of oneself may be negatively evaluated by others (Taylor et al., 2010). While social support provided by familiar persons was clearly identified by the participants, being confronted with uncontrollable and social-evaluative elements may jeopardize their previously constructed social esteem or status. This may be reinforced by the fact that being supported implies that the participant is unable to handle the stressful tasks on his own. It may be more difficult to bear in front of familiar persons because the need for positive selfpresentation and positive self-regard is not satisfied, which induces cortisol level increases (Dickerson \& Kemeny, 2004).

Self-reported anxiety was in our study significantly higher after the TSST-G than before for three conditions, but surprisingly not for the familiar/positive condition, in which participants also declared lower levels of anxiety than in the unfamiliar/positive condition. However, the review of Frisch et al. (2015) highlighted that social support did not affect self-reported anxiety in studies using the TSST. This is also the case in the study of Frisch et al. (2014) while a shared social identity was experimentally induced between the provider and the recipient of social support. One potential explanation of this difference is that familiarity does not reduce negative affect but elicits a positive one (Cacioppo \& Berntson, 1994). When a participant has a familiar relationship with the evaluative experimenters, he may feel the attentiveness and social support reassuring and more informative about the quality of his performance (Maisel \& Gable, 2009), which affects his subjectively experienced stress response, but not his neuroendocrine response. This difference is not surprising because a large majority of studies using experimental stressors did not show significant correlation between cortisol levels 
and self-reported anxiety (for a review see Campbell \& Ehlert, 2012). Participants in the familiar/positive condition may have some expectations concerning the social support provided by their teacher during the stressful tasks. Compared with the unfamiliar/positive condition, the two experimenters were certainly more responsive to the participants' needs in the familiar/positive condition, which may have led to decreases in self-reported anxiety. But this hypothesis remains speculative and needs to be validated.

Finally, salivary cortisol levels and state anxiety scores were not predicted by the level of closeness between participants and their teachers in the two familiar conditions. By contrast, Frisch et al. (2014) demonstrated that a shared social identity between participants and the committee members buffered the neuroendocrine stress response, but not the self-reported strain. The results of the present study are reversed. First, these two studies were rather different: closeness and shared social identity were related but distinct concepts (closeness implies more intimacy), and closeness pre-existed in our study, whereas shared social identity was experimentally manipulated in Frisch et al.'s study. Secondly, an obvious difference in hierarchical status exists between teachers and students, whereas participants and committee members were all students in Frisch et al.'s experiment. Despite the closeness reported by some participants, this hierarchical relationship between the providers (who are also the stressors) and the recipients of social support may prevent the creation of a shared social identity between teachers and students during evaluative tasks. Third, men are often faced with normative pressure and social-evaluative threat if they seek and benefit from emotional support in their close relationships (Burleson, Holmstrom, \& Gilstrap, 2005), which might explain why participants who are close to their teachers did not buffer their stress response even when the committee members were supportive.

\section{Limitations, future research, and conclusion}

People are constantly observed and evaluated by their social interaction partners (Frisch et al., 2015). When confronting the participants with the TSST, the results showed that familiarity and social support did not have stress-buffering effects on cortisol levels but buffered self-reported anxiety only for the students faced with a supportive audience composed of familiar teachers. Moreover, closeness between students and teachers was not a significant predictor of the stress responses when participants were evaluated through the TSST. Social-evaluative threat, information or expectations about the (in)competency of the support provider are always present even with friends or family, but they may be stronger or exacerbated in the teacher-student relationship because of the countless social-evaluative situations during lessons and examinations. But, on the other hand, familiarity and/ or closeness with close friends or family members is often stronger than that with teachers (e.g., Jehn \& Shah, 1997). For this reason, our results may be considered preliminary evidence. But other factors need to be taken into account. Despite the use of Bayes factor analyses, the rather small sample size increased the risk of type II-error and diminished the power of the study. Moreover, other categories of close others than teachers, with higher levels of familiarity and closeness such partner, friends, or family need to be studied in order to highlight if the pattern of results would be similar. Furthermore, the assessment of closeness was conducted with a visual analog scale, but a more precise measure of closeness may be more meaningful (e.g., Experiences in Close Relationships - Revised, Fraley, Heffernan, Vicary, \& Brumbaugh 2011). Taking into account these limitations and extending the present study to include women, other forms of social support such as tangible or appraisal support (Cohen \& McKay, 1984), and some moderators (e.g., sex of the committee members, personality variables) are promising ways to better understand when and why social support provided by evaluative familiar and close others may buffer or exacerbate stress.

\section{Disclosure statement}

No potential conflict of interest was reported by the authors. 


\section{References}

Allen, A. P., Kennedy, P. J., Cryan, J. F., Dinan, T. G., \& Clarke, G. (2014). Biological and psychological markers of stress in humans: Focus on the trier social stress test. Neuroscience \& Biobehavioral Reviews, 38, 94-124. doi:10.1016/j.neubiorev. 2013.11.005

Aron, A., Melinat, E., Aron, E. N., Vallone, R. D., \& Bator, R. J. (1997). The experimental generation of interpersonal closeness: A procedure and some preliminary findings. Personality and Social Psychology Bulletin, 23, 363-377. doi:10.1177/ 0146167297234003

Bolger, N., \& Amarel, D. (2007). Effects of social support visibility on adjustment to stress: Experimental evidence. Journal of Personality and Social Psychology, 92, 458-475. doi:10.1037/0022-3514.79.6.953

Burleson, B. R., Holmstrom, A. J., \& Gilstrap, C. M. (2005). "Guys can't say that to guys": four experiments assessing the normative motivation account for deficiencies in the emotional support provided by men. Communication Monographs, 72, 468-501. doi:10.1080/03637750500322636

Cacioppo, J. T., \& Berntson, G. G. (1994). Relationship between attitudes and evaluative space: A critical review, with emphasis on the separability of positive and negative substrates. Psychological Bulletin, 115, 401-423. doi:10.1037/ 0033-2909.115.3.401

Campbell, J., \& Ehlert, U. (2012). Acute psychosocial stress: Does the emotional stress response correspond with physiological responses? Psychoneuroendocrinology, 37, 1111-1134. doi:10.1016/j.psyneuen.2011.12.010

Carr, E. W., Brady, T. F., \& Winkielman, P. (2017). Are you smiling, or have I seen you before? Familiarity makes faces look happier. Psychological Science, 28(8), 1087-1102. doi:10.1177/0956797617702003

Charpentier, C. J., Hindocha, C., Roiser, J. P., \& Robinson, O. J. (2016). Anxiety promotes memory for mood-congruent faces but does not alter loss aversion. Scientific Reports, 6, 24746. doi:10.1038/srep24746

Cohen, S. (2004). Social relationships and health. American Psychologist, 59, 676-684. doi:10.1037/0003-066x.59.8.676

Cohen, S., \& McKay, G. (1984). Social support, stress and the buffering hypothesis: A theoretical analysis. In A. Baum, J. E. Singer, \& S. E. Taylor (Eds.), Handbook of psychology and health (pp. 253-267). Hillsdale, NJ: Erlbaum.

Depaoli, S., Rus, H. M., Clifton, J. P., van de Schoot, R., \& Tiemensma, J. (2017). An introduction to Bayesian statistics in health psychology. Health Psychology Review, 11(3), 248-264. doi:10.1080/17437199.2017.1343676

Dickerson, S. S., \& Kemeny, M. E. (2004). Acute stressors and cortisol responses: A theoretical integration and synthesis of laboratory research. Psychological Bulletin, 130, 355-391. doi:10.1037/0033-2909.130.3.355

Faul, F., Erdfelder, E., Buchner, A., \& Lang, A.-G. (2009). Statistical power analyses using G*power 3.1: Tests for correlation and regression analyses. Behavior Research Methods, 41, 1149-1160. doi:10.3758/brm.41.4.1149

Fraley, R. C., Heffernan, M. E., Vicary, A. M., \& Brumbaugh, C. C. (2011). The experiences in close relationships-relationship Structures Questionnaire: A method for assessing attachment orientations across relationships. Psychological Assessment, 23(3), 615-625. doi:10.1037/a0022898

Frisch, J. U., Häusser, J. A., \& Mojzisch, A. (2015). The Trier social stress test as a paradigm to study how people respond to threat in social interactions. Frontiers in Psychology, 6(14). doi:10.3389/fpsyg.2015.00014

Frisch, J. U., Häusser, J. A., van Dick, R., \& Mojzisch, A. (2014). Making support work: The interplay between social support and social identity. Journal of Experimental Social Psychology, 55, 154-161. doi:10.1016/j.jesp.2014.06.009

Fuchs, D., \& Fuchs, L. S. (1986). Test procedure bias: A meta-analysis of examiner familiarity effects. Review of Educational Research, 56(2), 243-262. doi:10.3102/00346543056002243

Haslam, S. A., Reicher, S. D., \& Levine, M. (2012). When other people are heaven, when other people are hell: How social identity determines the nature and impact of social support. In J. Jetten, C. Haslam, \& S. A. Haslam (Eds.), The social cure: Identity, health, and well-being (pp. 157-174). London: Psychology Press.

Jarosz, A. F., \& Wiley, J. (2014). What are the odds? A practical guide to computing and reporting Bayes factors. Journal of Problem Solving, 7, 2-9. doi:10.7771/1932-6246.1167

Jehn, K. A., \& Shah, P. P. (1997). Interpersonal relationships and task performance: An examination of mediation processes in friendship and acquaintance groups. Journal of Personality and Social Psychology, 72(4), 775-790. doi:10.1037/00223514.72.4.775

Kirschbaum, C., Pirke, K. M., \& Hellhammer, D. H. (1993). The 'trier social stress test' - a tool for investigating psychobiological stress responses in a laboratory setting. Neuropsychobiology, 28, 76-81. doi:10.1159/000119004

Kors, D. J., Linden, W., \& Gerin, W. (1997). Evaluation interferes with social support: Effects on cardiovascular stress reactivity in women. Journal of Social \& Clinical Psychology, 16, 1-23. doi:10.1521/jscp.1997.16.1.1

Lam, S., Dickerson, S. S., Zoccola, P. M., \& Zaldivar, F. (2009). Emotion regulation and cortisol reactivity to a social-evaluative speech task. Psychoneuroendocrinology, 34(9), 1355-1362. doi:10.1016/j.psyneuen.2009.04.006

Maisel, N. C., \& Gable, S. L. (2009). The paradox of received social support: The importance of responsiveness. Psychological Science, 20, 928-932. doi:10.1111/j.1467- 9280.2009.02388.x

Malecki, C. K., \& Demaray, M. K. (2003). What type of support do they need? Investigating student adjustment as related to emotional, informational, appraisal, and instrumental support. School Psychology Quarterly, 18, 231-252. doi:10.1521/ scpq.18.3.231.22576 
Mascret, N., Ibáñez-Gijón, J., Bréjard, V., Buekers, M., Casanova, R., Marqueste, T., ... Cury, F. (2016). The influence of the 'trier social stress test'on free throw performance in basketball: An interdisciplinary study. PLoS One, 11, e0157215. doi:10.1371/journal.pone.0157215

Pabst, S., Brand, M., \& Wolf, O. T. (2013). Stress effects on framed decisions: There are differences for gains and losses. Frontiers in Behavioral Neuroscience, 7(142). doi:10.3389/fnbeh.2013.00142

Reis, H. T., Maniaci, M. R., Caprariello, P. A., Eastwick, P. W., \& Finkel, E. J. (2011). Familiarity does indeed promote attraction in live interaction. Journal of Personality and Social Psychology, 101(3), 557-570. doi:10.1037/a0022885

Rouder, J. N., Morey, R. D., Speckman, P. L., \& Province, J. M. (2012). Default Bayes factors for ANOVA designs. Journal of Mathematical Psychology, 56(5), 356-374. doi:10.1016/j.jmp.2012.08.001

Smith, A. M., Loving, T. J., Crockett, E. E., \& Campbell, L. (2009). What's closeness got to do with it? Men's and women's cortisol responses when providing and receiving support. Psychosomatic Medicine, 71(8), 843-851. doi:10.1097/psy. ob013e3181b492e6

Sollberger, S., Bernauer, T., \& Ehlert, U. (2016). Stress influences environmental donation behavior in men. Psychoneuroendocrinology, 63, 311-319. doi:10.1016/j.psyneuen.2015.10.017

Spielberger, C. D. (1993). STAI-Y: Inventaire d'anxiété état-trait forme Y. Éditions du centre de psychologie appliquée.

Stalder, T., Kirschbaum, C., Kudielka, B. M., Adam, E. K., Pruessner, J. C., Wüst, S., ... Clow, A. (2016). Assessment of the cortisol awakening response: Expert consensus guidelines. Psychoneuroendocrinology, 63, 414-432. doi:10.1016/j. psyneuen.2015.10.010

Taylor, S. E. (2007). Social support. In H. S. Friedman, \& R. C. Silver (Eds.), Foundations of health psychology (pp. 145-171). New York: Oxford University Press.

Taylor, S. E., Seeman, T. E., Eisenberger, N. I., Kozanian, T. A., Moore, A. N., \& Moons, W. G. (2010). Effects of a supportive or an unsupportive audience on biological and psychological responses to stress. Journal of Personality and Social Psychology, 98, 47-56. doi:10.1037/a0016563

van den Bos, R., Harteveld, M., \& Stoop, H. (2009). Stress and decision-making in humans: Performance is related to cortisol reactivity, albeit differently in men and women. Psychoneuroendocrinology, 34, 1449-1458. doi:10.1016/j. psyneuen.2009.04.016

von Dawans, B., Kirschbaum, C., \& Heinrichs, M. (2011). The trier social stress test for groups (TSST-G): A new research tool for controlled simultaneous social stress exposure in a group format. Psychoneuroendocrinology, 36, 514-522. doi:10. 1016/j.psyneuen.2010.08.004 